\title{
Dopant dependence on passivation and reactivation of carrier after hydrogenation
}

\author{
N. Fukata, ${ }^{a), b)}$ S. Sato, H. Morihiro, and K. Murakami ${ }^{\text {b) }}$ \\ Institute of Applied Physics, University of Tsukuba, 1-1-1 Tennodai, Tsukuba 305-8573, Japan
}

\begin{abstract}
K. Ishioka and M. Kitajima ${ }^{\text {b) }}$ 0047, Japan

\section{S. Hishita}

Advanced Materials Laboratory, National Institute for Materials Science,

Tsukuba 305-0044, Japan
\end{abstract}

Materials Engineering Laboratory, National Institute for Materials Science, 1-2-1 Sengen, Tsukuba 305-

(Received 17 December 2006; accepted 3 January 2007; published online 26 February 2007)

\begin{abstract}
The formation of hydrogen (H)-related complexes and $\mathrm{H}$ effects on boron $(\mathrm{B})$ and phosphorus $(\mathrm{P})$ dopants was investigated in $\mathrm{B}$ - or P-doped silicon $(\mathrm{Si})$ crystal treated with high concentration of $\mathrm{H}$. The reactivation process of dopant carriers by annealing after hydrogenation was significantly different between the $p$-type and $n$-type specimens. The difference is likely to be attributable to the formation of $\mathrm{H}$-related defects based on the stable sites of the $\mathrm{H}$ atoms, i.e., complicated $\mathrm{H}$ multiple trapping centers are formed by bond breaking due to $\mathrm{H}$ atoms in only p-type B-doped Si. (C) 2007 American Institute of Physics. [DOI: 10.1063/1.2654831]
\end{abstract}

Hydrogen $(\mathrm{H})$ is an important impurity in $\mathrm{Si}$, so its properties have been extensively studied. ${ }^{1}$ In particular, $\mathrm{H}$ passivation of acceptors and donors is one of the most important topics from both fundamental and technological points of view. ${ }^{1}$ The structures and behaviors of the passivation centers are significantly different between $p$-type $\mathrm{Si}$ and $n$-type $\mathrm{Si}^{1-10}$ In $p$-type B-doped silicon, a $\mathrm{H}$ atom is located at the bond-centered (BC) site between $\mathrm{B}$ and a neighboring host $\mathrm{Si}$ atom. ${ }^{5-7,9}$ This structure is a so-called $\mathrm{H}-\mathrm{B}$ passivation center. On the other hand, in $n$-type $\mathrm{P}$-doped $\mathrm{Si}$, the $\mathrm{H}$ atom is located at the anitibonding (AB) site of the nearest Si neighbor to a $\mathrm{P}$ atom, forming a $\mathrm{P}-\mathrm{Si}-\mathrm{H}$ passivation center. ${ }^{3-5,7,9}$

In addition to the passivation centers, hydrogen molecules ${ }^{11-15}$ and extended planar defects called platelets ${ }^{16,17}$ are formed with increasing $\mathrm{H}$ concentration introduced into $\mathrm{Si}$. The formation of hydrogen molecules and platelets also depends on the types of dopant impurities in $\mathrm{Si}^{18,19}$ Furthermore, $\mathrm{H}$ multiple trapping centers are formed in heavily H- and B-doped $\mathrm{Si}^{20,21}$ Recently, some of them have been assigned to B-H complexes in which multiple $\mathrm{H}$ atoms are trapped, and at least one of them directly bonds to the $\mathrm{B}$ in $\mathrm{Si}^{21}{ }^{21}$ The effect of the $\mathrm{B}-\mathrm{H}$ complexes on B dopants such as passivation has been investigated in our previous work ${ }^{21}$ whereas the recovery of $\mathrm{B}$ dopants by the dissociation of $\mathrm{H}$ atoms from the complexes has not yet been investigated. As for $n$-type Si, neither the formation of such $\mathrm{H}$ multiple trapping centers nor their effect on $n$-type dopants has been investigated.

In the present study, the formation of H-related complexes and their influence on B or P dopants was investigated

\footnotetext{
${ }^{a}$ Present address: Advanced Electronic Materials Center, National Institute for Materials Science, 1-1 Namiki, Tsukuba 305-0044, Japan; electronic mail: fukata.naoki@nims.go.jp

b) Also at Special Research Project of Nano-Science, University of Tsukuba, 1-1-1 Tennodai, Tsukuba 305-8573, Japan.
}

in hydrogenated $p$-type B-doped $\mathrm{Si}$ and hydrogenated $n$-type $P$-doped $\mathrm{Si}$, respectively. The reactivation of dopants by thermal annealing was also investigated. The outcomes were significantly different between $p$-type and $n$-type specimens.

Two types of specimens were used in this study. One was $n$-type Czochralski $(\mathrm{Cz})-\mathrm{Si}(1.4-2.3 \Omega \mathrm{cm})$ implanted with $30 \mathrm{keV}{ }^{11} \mathrm{~B}^{+}$ions at a dose of $1 \times 10^{15} \mathrm{~cm}^{-2}$. The other was $p$-type $\mathrm{Si}(50 \Omega \mathrm{cm})$ implanted with $50 \mathrm{keV} \mathrm{P}^{+}$ions at a dose of $1 \times 10^{15} \mathrm{~cm}^{-2}$. These implanted $\mathrm{Si}$ samples were annealed in a $\mathrm{N}_{2}$ gas atmosphere at $900{ }^{\circ} \mathrm{C}$ for $30 \mathrm{~min}$ to electrically activate the dopants. Hereafter, we, respectively, term these specimens $p$-type B-doped $\mathrm{Si}$ and $n$-type P-doped $\mathrm{Si}$. After the specimens were activated, they were hydrogenated by hydrogen atom treatments (HATs) at temperatures ranging from 100 to $330{ }^{\circ} \mathrm{C}$. The details of the hydrogenation procedure and conditions are reported elsewhere. ${ }^{8,21}$ Raman scattering measurements were performed at RT with a $514.5 \mathrm{~nm}$ excitation beam at a power of $100 \mathrm{~mW}$. Resistivity measurements were performed at RT using four-point probe measurements. Electron spin resonance (ESR) measurements were carried out at $4.2 \mathrm{~K}$ using an $X$-band spectrometer with a magnetic field modulation of $100 \mathrm{kHz}$.

The representative Raman spectra observed in $p$-type B-doped $\mathrm{Si}$ and $n$-type P-doped $\mathrm{Si}$ after hydrogenation at $190{ }^{\circ} \mathrm{C}$ for $30 \mathrm{~min}$ are shown in Fig. 1. Several peaks were observed in the hydrogenated $p$-type B-doped Si. The peak at $1873 \mathrm{~cm}^{-1}$ is due to the well-known H-B passivation center. The peaks at $2283,2376,2387$, and $2470 \mathrm{~cm}^{-1}$ were assigned in our previous study ${ }^{21}$ to the B-H stretching mode of $\mathrm{B}-\mathrm{H}$ complexes in which $\mathrm{H}$ atoms directly bond with $\mathrm{B}$ atoms. $^{21}$ The other peaks at 1931, 2105, 2134, 2222, and $2241 \mathrm{~cm}^{-1}$ are due to $\mathrm{Si}-\mathrm{H}$ stretching modes of defects formed by hydrogenation. ${ }^{21}$ Notably, the peak at $2134 \mathrm{~cm}^{-1}$ is due to the $\mathrm{Si}-\mathrm{H}$ stretching mode of platelets, ${ }^{16,17,22}$ which are known as hydrogen-related planar defects in Si. Hereaf- 


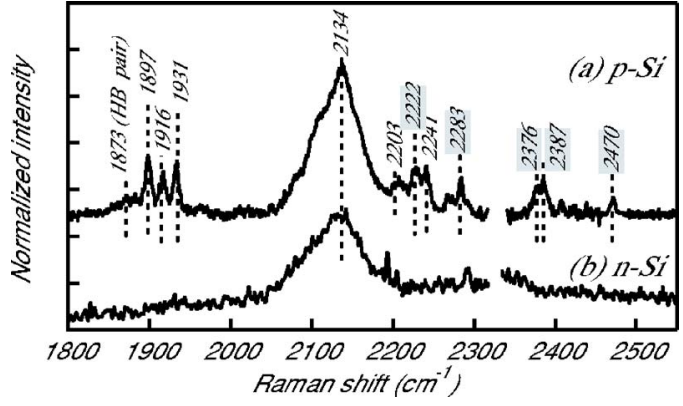

FIG. 1. Raman spectra observed for (a) p-type B-doped Si and (b) n-type $\mathrm{P}$-doped Si after hydrogenation at $190{ }^{\circ} \mathrm{C}$ for $30 \mathrm{~min}$. The frequencies of the peaks related to $\mathrm{B}-\mathrm{H}$ complexes are shadowed.

ter, we term these defects related to $\mathrm{Si}-\mathrm{H}$ stretching modes "Si-H defects" except for the platelet defects. On the other hand, in the hydrogenated $n$-type P-doped $\mathrm{Si}$, only the peak due to the $\mathrm{Si}-\mathrm{H}$ stretching mode of platelets was observed. The observation of a $\mathrm{H}$-stretching mode in the $\mathrm{P}-\mathrm{Si}-\mathrm{H}$ passivation centers is generally difficult because of background phonon band. These results show that the formation of $\mathrm{H}$-related defects is markedly different between $p$-type $\mathrm{Si}$ and $n$-type $\mathrm{Si}$.

Figure 2(a) shows the dependence of the resistivity in $p$-type and $n$-type specimens on hydrogenation temperature. Figure 2(b) shows the hydrogenation temperature dependence of the H-related Raman peaks in p-type B-doped Si. The results for $p$-type specimens have been reported in our previous paper. ${ }^{21}$ Here, the increase in the hydrogenation temperature causes the increase in the quantity of $\mathrm{H}$ atoms introduced into specimens. The dependence is significantly different between $p$-type and $n$-type specimens. In the $p$-type specimen, the resistivity first increased with increasing hydrogenation temperature and then decreased as a result of hydrogenation above $220{ }^{\circ} \mathrm{C}$. As previously reported, ${ }^{21}$ the increase in the resistivity at $120^{\circ} \mathrm{C}$ from the value before

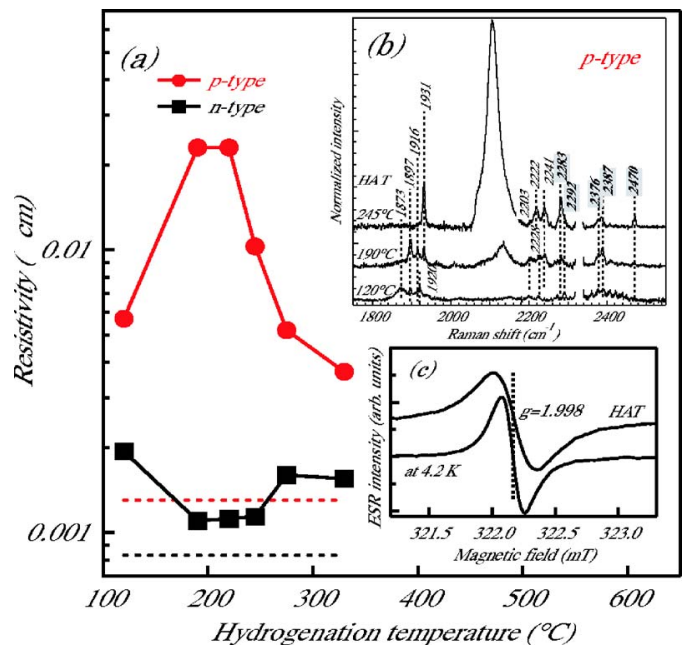

FIG. 2. (Color online) (a) Dependence of the resistivity of hydrogenated $p$-type B-doped $\mathrm{Si}$ and $n$-type $\mathrm{P}$-doped $\mathrm{Si}$, respectively. The dotted lines show the resistivity before HAT. (b) Raman spectra observed for $p$-type B-doped Si hydrogenated at different temperatures. The frequencies of the peaks related to B-H complexes are shadowed. (c) ESR signal of conduction electrons observed before and after HAT at $120{ }^{\circ} \mathrm{C}$ for $n$-type P-doped Si.
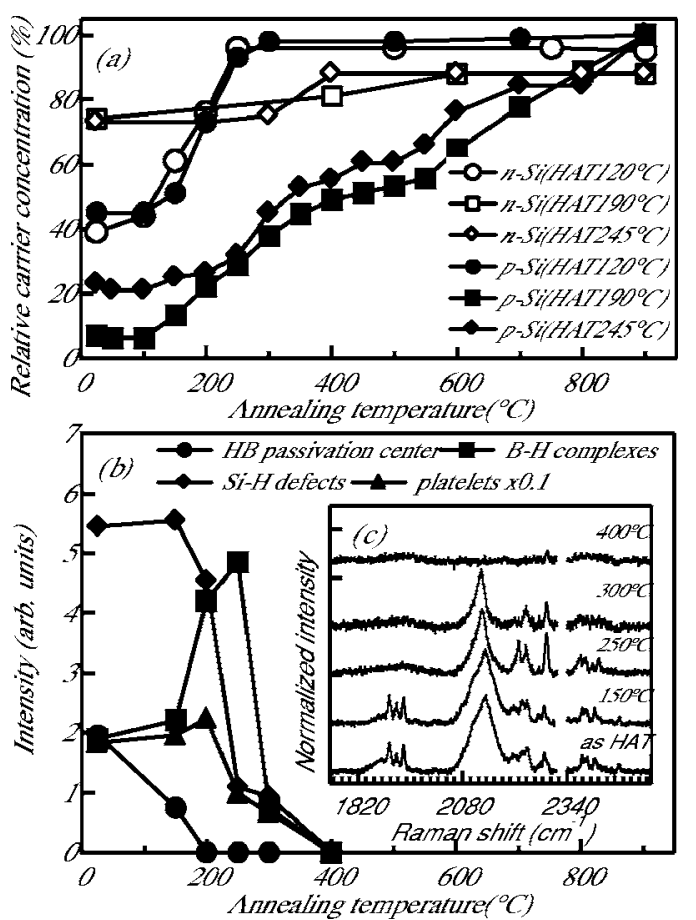

FIG. 3. (a) Isochronal annealing behaviors of the resistivity of $p$-type B-doped Si and n-type P-doped Si hydrogenated at 120, 190, and $245^{\circ} \mathrm{C}$, respectively. The isochronal annealing behaviors of (b) the peak intensities of the H-related Raman peaks and (c) their H-related Raman peaks for $p$-type B-doped Si hydrogenated at $190^{\circ} \mathrm{C}$.

hydrogenation is due to the passivation of $\mathrm{B}$ by $\mathrm{H}$. The further increase in the resistivity by hydrogenation at $190-220^{\circ} \mathrm{C}$ is mainly explained by the formation of the $\mathrm{B}-\mathrm{H}$ complexes. The gradual decrease in the resistivity with increasing hydrogenation temperature from $220^{\circ} \mathrm{C}$ can be explained by loss of $\mathrm{H}-\mathrm{B}$ passivation centers and finally B-H complexes. On the other hand, the dependence seen in the $n$-type specimens was quite different. The increase at $120^{\circ} \mathrm{C}$ from the value before HAT is due to the formation of $\mathrm{P}-\mathrm{Si}-\mathrm{H}$ passivation centers, resulting in $\mathrm{H}$ passivation of $\mathrm{P}$. The decrease at $190{ }^{\circ} \mathrm{C}$ is due to the decreased formation of $\mathrm{P}-\mathrm{Si}-\mathrm{H}$ passivation centers. The formation of the $\mathrm{P}-\mathrm{Si}-\mathrm{H}$ passivation centers can be investigated by ESR measurements, as shown in Fig. 2(c). The ESR signal with a $g$ value of 1.998 is due to conduction electrons in $n$-type P-doped $\mathrm{Si}^{8,23,24}$ The width significantly depends on $\mathrm{P}$ concentration. $^{23,24}$ If the width would be decreased for the heavily $\mathrm{P}$-doped $\mathrm{Si}$, it means the passivation of $\mathrm{P}$. The result in Fig. 2(c) clearly shows the decrease in the width by HAT, indicating the $\mathrm{H}$ passivation of $\mathrm{P}$ by forming the $\mathrm{P}-\mathrm{Si}-\mathrm{H}$ passivation centers. Considering the previous results, ${ }^{23,24}$ it is found that $50 \%-60 \%$ of active $\mathrm{P}$ dopant was passivated by HAT at $120^{\circ} \mathrm{C}$. This result is in good agreement with that in Fig. 3 shown later. The increase from the temperature at $245^{\circ} \mathrm{C}$ is probably due to the effect of the platelets, since only the Raman spectrum of the platelets is observed in this temperature range. This result suggests that the resistivity in $p$-type specimen is also affected by the platelets.

The relationships between the annihilation of H-related centers and the reactivation rate of carrier were investigated by isochronal annealing, as shown in Fig. 3. The annealing 
behavior for the specimen hydrogenated at $120{ }^{\circ} \mathrm{C}$ showed a similar dependence between $p$-type and $n$-type specimens. The increases in active carrier concentration are due to the dissociation of the $\mathrm{H}-\mathrm{B}$ passivation center and that of the $\mathrm{P}-\mathrm{Si}-\mathrm{H}$ passivation center, respectively, resulting in the reactivation of the dopants. On the other hand, the annealing behaviors for the specimen hydrogenated at 190 and $245^{\circ} \mathrm{C}$ are significantly different between $p$-type and $n$-type specimens. In the case of $n$-type specimens, the annealing behaviors can be explained by the annihilation of platelets, since only platelets are formed in the hydrogenation temperature range. In the case of $p$-type specimens, the behaviors are complicated, and annealing at around $900{ }^{\circ} \mathrm{C}$ is necessary to almost perfectly reactivate B dopants.

To explain the complicated behavior, the annealing behaviors of $\mathrm{H}$-related Raman peaks were investigated for $p-\mathrm{Si}$ $\left(\right.$ HAT of $190{ }^{\circ} \mathrm{C}$ ). The results are shown in Figs. 3(b) and 3 (c). The activation process of the dopant carrier is roughly divided into three parts, the first being $100-250{ }^{\circ} \mathrm{C}$, the second $250-500{ }^{\circ} \mathrm{C}$, and the third $500-900{ }^{\circ} \mathrm{C}$. The first part can be satisfactorily explained by the presence of $\mathrm{H}-\mathrm{B}$ passivation centers. The effect of the $\mathrm{H}-\mathrm{B}$ passivation centers is evident in the difference between $p$-Si (HAT of $190{ }^{\circ} \mathrm{C}$ ) and $p$-Si (HAT of $245^{\circ} \mathrm{C}$ ). The active carrier concentration in the first part of $p$-Si (HAT of $245^{\circ} \mathrm{C}$ ) is virtually constant because the $\mathrm{H}-\mathrm{B}$ passivation center is not formed at $245^{\circ} \mathrm{C}$. On the other hand, the case of $p$-Si (HAT of $190{ }^{\circ} \mathrm{C}$ ) showed a similar dependence to that of $p$-Si (HAT of $120^{\circ} \mathrm{C}$ ), meaning that the annealing behavior in this part can be satisfactorily explained by the dissociation of $\mathrm{H}$ atoms from the $\mathrm{H}-\mathrm{B}$ passivation centers. In the second part, the behaviors are closely similar between $p$-Si (HAT of $245^{\circ} \mathrm{C}$ ) and $p$-Si (HAT of $190{ }^{\circ} \mathrm{C}$ ). This is because the same H-related complexes are formed in their specimens. The annealing behaviors of the active carrier concentration showed inverse correlations with those of the Raman intensities of platelets, B-H complexes, and $\mathrm{Si}-\mathrm{H}$ defects, suggesting that they can be explained by the annihilation of these defects, resulting in reactivation of the dopant carriers. In the third part, the reactivation rate is not still perfect, even after no H-related Raman peaks were observed, suggesting the existence of residual defects.

The difference between $p$-type and $n$-type specimens is mainly attributable to the difference in the stable site of the $\mathrm{H}$ atom within, and thereby the formation of H-related defects. As already described, a $\mathrm{H}$ atom is stable at the $\mathrm{BC}$ site between $\mathrm{B}$ and a neighboring host $\mathrm{Si}$ atom in $p$-type $\mathrm{B}$-doped $\mathrm{Si}^{5-7,9}$ The $\mathrm{H}$ bonds primary to the $\mathrm{Si}$, while the $\mathrm{B}$ moves away from this $\mathrm{Si}$ almost into the plane of the other three $\mathrm{Si}$ neighbors, meaning the $\mathrm{Si}-\mathrm{B}$ bond is broken. As already reported, such bond breaking is stepped up by introducing high concentrations of $\mathrm{H}$ atoms, with, ultimately, complicated $\mathrm{H}$ multiple trapping centers such as $\mathrm{B}-\mathrm{H}$ complexes being formed in $p$-type $\mathrm{B}$-doped $\mathrm{Si}^{21}$ These complicated $\mathrm{H}$ multiple trapping centers are considered to act as residual defects even after the $\mathrm{H}$ atoms have dissociated from the defect centers, retarding the reactivation of the dopants. On the other hand, the most stable site for a $\mathrm{H}$ atom in $n$-type $\mathrm{P}$-doped $\mathrm{Si}$ is the $\mathrm{AB}$ site of the nearest Si neighbor to a $\mathrm{P}$ atom. ${ }^{3-5,7,9} \mathrm{In}$ this case, the $\mathrm{Si}-\mathrm{P}$ bond is not broken. Hence, complicated $\mathrm{H}$ multiple trapping centers such as those seen in $p$-type B-doped $\mathrm{Si}$ are not formed in $n$-type $\mathrm{P}$-doped $\mathrm{Si}$, resulting in reactivation at lower temperatures. Finally, a problem remains: P dopants were not perfectly activated in $n$-type $\mathrm{Si}$ (HATs of 190 and $245^{\circ} \mathrm{C}$ ). To clarify the cause, we checked the effect of the metal probes used in resistivity measurements. The problem is, however, not solved. The change in the $\mathrm{P}$ dopant profile resulting from annealing might also be one possibility.

In conclusion, the formation of H-related complexes and their effects on B and $\mathrm{P}$ dopants were investigated in B- or P-doped Si treated with high concentrations of $\mathrm{H}$. The dependence of the resistivity on hydrogenation temperature and the reactivation process of the dopant carrier were markedly different in $p$-type and $n$-type specimens. The difference is likely to be due to the stable sites of the $\mathrm{H}$ atom within them and thereby the formation of H-related defects, i.e., complicated $\mathrm{H}$ multiple trapping centers are easily formed by bond breaking due to $\mathrm{H}$ atoms in only $p$-type specimens.

${ }^{1}$ See Hydrogen in Semiconductors, edited by J. I. Pankove and N. M. Johnson Semiconductors and Semimetals Vol. 34, (Academic, New York, 1991).

${ }^{2}$ J. I. Pankove, D. E. Carlson, J. E. Berkeyheiser, and R. O. Wance, Phys. Rev. Lett. 51, 2224 (1983).

${ }^{3}$ N. M. Johnson, C. Herring, and D. J. Chadi, Phys. Rev. Lett. 56, 769 (1986).

${ }^{4}$ K. Bergman, M. Stavola, S. J. Pearton, and J. Lopata, Phys. Rev. B 37, 2770 (1988)

${ }^{5}$ K. J. Chang and D. J. Chadi, Phys. Rev. Lett. 60, 1422 (1988).

${ }^{6}$ P. J. H. Denteneer, C. G. van de Walle, and S. T. Pantelides, Phys. Rev. B 39, 10809 (1989).

${ }^{7}$ S. K. Estreicher, L. Throckmorton, and D. S. Marynick, Phys. Rev. B 39, 13241 (1989).

${ }^{8}$ N. Fukata, S. Sasaki, S. Fujimura, H. Haneda, and K. Murakami, Jpn. J. Appl. Phys., Part 1 35, 3937 (1996).

${ }^{9}$ C. Herring, N. M. Johnson, and C. G. van de Walle, Phys. Rev. B 64, 125209 (2001).

${ }^{10}$ T. Zundel and J. Weber, Phys. Rev. B 43, 4361 (1991).

${ }^{11}$ R. E. Pritchard, M. J. Ashwin, J. H. Tucker, R. C. Newman, E. C. Lightowlers, M. J. Binns, S. A. McQuaid, and R. Falster, Phys. Rev. B 56, 13118 (1997).

${ }^{12}$ A. W. R. Leitch, V. Alex, and J. Weber, Phys. Rev. Lett. 81, 421 (1998).

${ }^{13}$ K. Murakami, N. Fukata, S. Sasaki, K. Ishioka, M. Kitajima, S. Fujimura, J. Kikuchi, and H. Haneda, Phys. Rev. Lett. 77, 3161 (1996).

${ }^{14}$ M. Kitajima, K. Ishioka, K. Nakanoya, S. Tateishi, T. Mori, N. Fukata, K. Murakami, and S. Hishita, Jpn. J. Appl. Phys., Part 2 38, L691 (1999).

${ }^{15}$ E. E. Chen, M. Stavola, W. B. Fowler, and P. Walters, Phys. Rev. Lett. 88, 105507 (2002).

${ }^{16}$ N. M. Johnson, F. A. Ponce, R. A. Street, and R. J. Nemanish, Phys. Rev. B 35, 4166 (1987).

${ }^{17}$ Y. Ma, Y. L. Huang, W. Düngen, R. Job, and W. R. Fahrner, Phys. Rev. B 72, 085321 (2005)

${ }^{18}$ K. Ishioka et al., Jpn. J. Appl. Phys., Part 1 42, 5410 (2003).

${ }^{19}$ N. H. Nickel, G. B. Anderson, N. M. Johnson, and J. Walker, Phys. Rev. B 62, 8012 (2000)

${ }^{20}$ L. Korpas, J. W. Corbett, and S. K. Estreicher, Phys. Rev. B 46, 12365 (1992).

${ }^{21}$ N. Fukata, S. Fukuda, S. Sato, K. Ishhioka, M. Kitajima, T. Hishita, and K. Murakami, Phys. Rev. B 72, 245209 (2005).

${ }^{22}$ N. Fukata et al., Phys. Rev. B 56, 6642 (1997).

${ }^{23}$ S. Maekawa and N. Kinishita, J. Phys. Soc. Jpn. 20, 1447 (1965).

${ }^{24}$ J. D. Quirt and J. R. Marko, Phys. Rev. B 5, 1716 (1972). 